\title{
Seagrass Halophila ovalis is affected by light quality across different life history stages
}

\author{
Simone Strydom ${ }^{1,2, *}$, Kathryn McMahon ${ }^{1,2}$, Gary A. Kendrick ${ }^{2,4}$, John Statton ${ }^{2,3}$, \\ Paul S. Lavery ${ }^{1,2,4}$ \\ ${ }^{1}$ Centre for Marine Ecosystems Research and School of Science, Edith Cowan University, Joondalup, WA 6027, Australia \\ ${ }^{2}$ Western Australian Marine Science Institution, The University of Western Australia, Crawley, WA 6009, Australia \\ ${ }^{3}$ School of Biological Sciences, University of Western Australia, Nedlands, WA 6009, Australia \\ ${ }^{4}$ Centro de Estudios Avanzados de Blanes, Consejo Superior de Investigaciones Científicas, 17300 Blanes, Spain
}

\begin{abstract}
Seagrass meadows provide crucial ecosystem services to the coastal zone but are threatened globally. Seagrass loss to date has mainly been attributed to anthropogenic activities that reduce light quantity (amount of photosynthetic photon flux density), such as dredging, flooding and eutrophication. However, light quality (wavelengths of light within the visible spectrum) is also altered by these anthropogenic stressors. This study addressed the effect of light quality changes on seagrasses. Aquarium-based experiments were conducted to determine whether the seagrass Halophila ovalis (R.Br.) Hook f. responds to different light quality treatments. Separate experiments were performed in which adults, seeds or seedlings were subjected to monochromatic light treatments in the blue (peak $\lambda=451 \mathrm{~nm}$ ), green (peak $\lambda=522 \mathrm{~nm}$ ), yellow (peak $\lambda=596 \mathrm{~nm}$ ) and red (peak $\lambda=673 \mathrm{~nm}$ ) wavelengths with a control of full-spectrum light ( $\lambda=400-700 \mathrm{~nm}$, at $200 \mu \mathrm{mol}$ photons $\mathrm{m}^{-2} \mathrm{~s}^{-1}$ ). This study is unique in that it measured seagrass responses to light across several plant scales (physiology, productivity, morphology and biomass) as well as across life-history stages (seeds, seedlings, adults and flowering). Adult plants responded differently to seeds and seedlings but were generally consistent with terrestrial angiosperms: blue light decreased below-ground productivity; green light influenced morphology (through increased rhizome internode length); red light enhanced seed germination and survival. The findings indicate that both natural and human-induced changes in light quality could significantly affect seagrass growth and reproduction. As a range of anthropogenic activities are currently contributing to the global losses of seagrasses, this research provides timely information on how light quality influences different seagrass life history stages.
\end{abstract}

KEY WORDS: Light quality · Photomorphogenesis $\cdot$ Plant growth $\cdot$ Seagrass $\cdot$ Seed germination Seedling survival

\section{INTRODUCTION}

A plant's life cycle is inextricably linked to changes in light quality (the composition of the wavelengthspecific radiation within the electromagnetic spectrum (from UV to far-red light, 300 to $760 \mathrm{~nm}$ )) and light quantity (the total amount of light or photosynthetic photon flux density). In terrestrial plants, critical plant processes influenced by light quality include setting of circadian rhythms, flower induction, seed germination, photosynthesis and adult

\footnotetext{
${ }^{*}$ Corresponding author: s.strydom@ecu.edu.au
}

and seedling growth (Fankhauser \& Chory 1997, Whitelam \& Halliday 2008). Due to the shared ancestry with terrestrial plants, seagrasses would be expected to have the ability to detect and respond to shifts in the quality of light in much the same way. However, due to their long evolutionary history in the marine environment, up to 85 million years (Les et al. 1997), and the spectral attenuation through sea water, seagrasses may have developed different sensitivities and responses to changes in light quality.

() The authors 2017. Open Access under Creative Commons by Attribution Licence. Use, distribution and reproduction are unrestricted. Authors and original publication must be credited. 
Terrestrial plants perceive, monitor and respond to changes in light quality through photoreceptors that initiate signal transduction cascades leading to a range of physiological, growth and morphological responses. The phytochrome family (phyA-phyE) efficiently absorbs red and far red light, whereas cryptochromes (cry1 and cry2) and phototropins (phot1 and phot2) mainly absorb UV-A and blue light (Casal 2000). The effects of illuminating terrestrial plants with different monochromatic light have been measured in many species (Fig. 1). Examples include the decrease in yarrow Achillea millefolium and cucumber seedling Cucumis sativus biomass in response to blue light, as well as reduced rooting in yarrow and Phyllanthus tenellus (Su et al. 2014, Alvarenga et al. 2015). Often, there is variability among responses to light quality across the plant scale: for example, maximal photochemical efficiency and quantum yield of
PSII of leaves growing under blue light was significantly higher than under control light, whilst biomass under blue light was significantly lower than under control light (Su et al. 2014). Furthermore, responses are often species-specific; monochromatic blue light enhanced germination in orchids Cattleya walkeriana but not in Amaranthus caudatus seeds (Nowak et al. 1996, Islam et al. 1999) (Fig. 1).

The wide range of plant responses to light quality reflects adaptations to habitats that undergo spectral shifts both in space and over a range of timescales. For example, in terrestrial ecosystems, light quality changes through forest canopies as the upper foliage absorbs blue and red light, with understory plants receiving reduced quantity and a green-enriched quality of light (Folta \& Maruhnich 2007). Plants can respond to this under-canopy light by altering their morphology (i.e. shade-avoidance response; Neff et al. 2000).

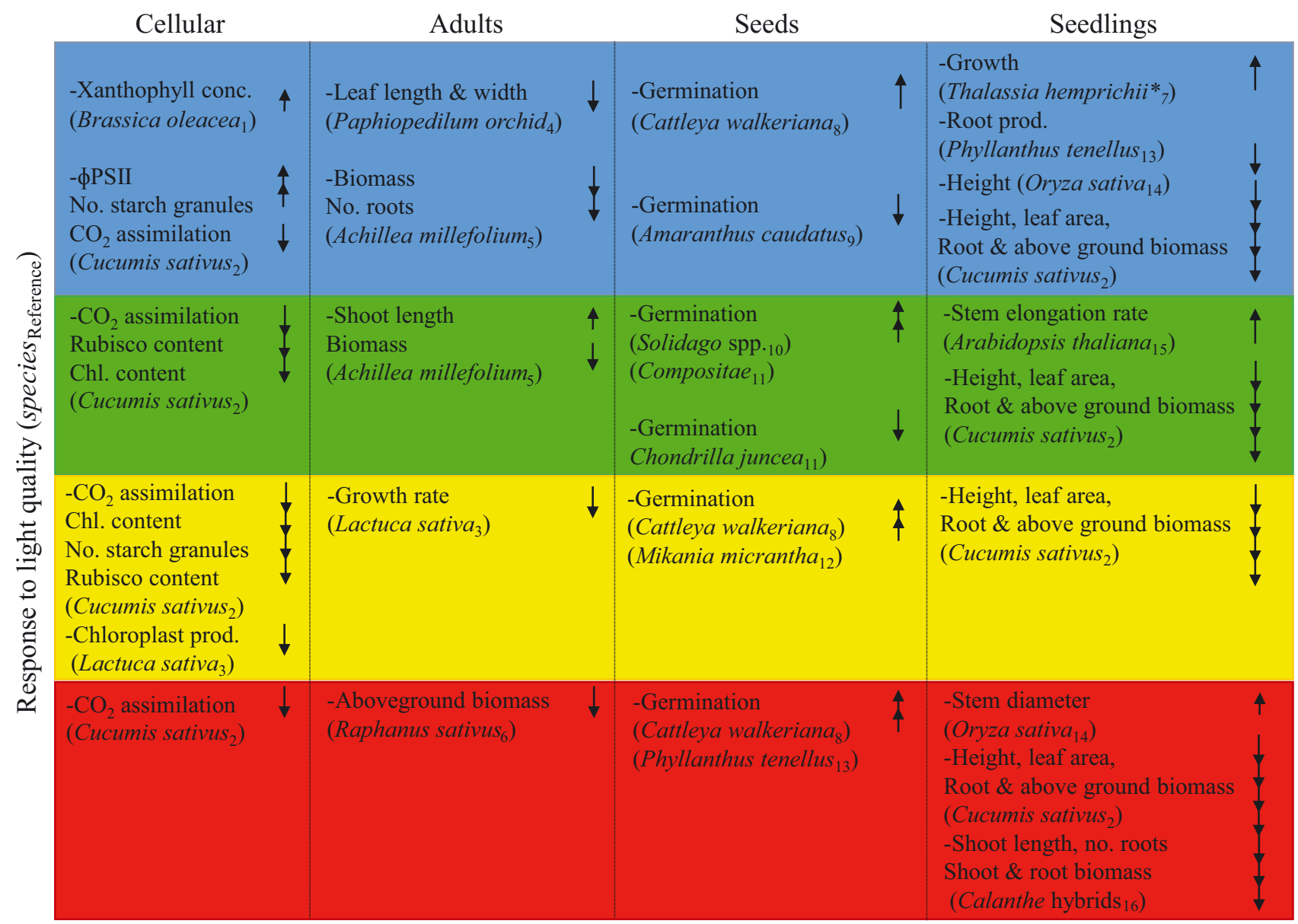

Fig. 1. Conceptual illustration of recent studies (within the last 2 decades) that found significant cellular, adult plant, seed and seedling responses (arrows) under monochromatic (blue, green, yellow and red) light quality treatments compared to fullspectrum or control white light. Asterisk: seagrass species. References: 1 (Kopsell \& Sams 2013), 2 (Su et al. 2014 ), 3 (Dougher \& Bugbee 2001), 4 (Lee et al. 2011), 5 (Alvarenga et al. 2015), 6 (Drozdova et al. 2001), 7 (Soong et al. 2013 ), 8 (Islam et al. 1999), 9 (Nowak et al. 1996), 10 (Walck et al. 2000), 11 (Luna et al. 2004), 12 (Qi-He et al. 2005), 13 (Victorio \& Lage 2009), 14 (Guo et al. 2011), 15 (Folta 2004), 16 (Baque et al. 2011) 
Green light has been shown to induce rapid elongation of etiolated seedlings (that have negligible chlorophyll) and is efficiently transmitted through the leaves as much as other visible wavelengths (Folta 2004, Folta \& Maruhnich 2007). In aquatic, estuarine and marine ecosystems, a number of factors can drive strong shifts in light quality. Red light is rapidly attenuated by water so that blue light dominates at depths greater than $\sim 10 \mathrm{~m}$ in low-CDOM and oceanic systems (Kirk 1994). Suspended particles in the water, such as sediments and photosynthetic biota, and dissolved materials such as chromophoric dissolved organic matter (CDOM or gilvin) all affect the absorbance or scattering of light (Kirk 1994). For example, coastal waters with significant run-off or river input from forested watersheds expel high concentrations of CDOM, which exponentially absorbs short wavelength radiation and leads to a red-shifted light field (Kirk 1994). Consequently, the spectral quality of light changes with depth but can also vary among locations of the same depth depending on the particulate and dissolved components of water (Fig. 2). As light quality underwater changes according to depth and the inherent optical properties of components within the water (Kirk 1994), it is likely that submerged aquatic vegetation respond to these shifts.

Seagrasses are a polyphyletic group of marine angiosperms that evolved from monocotyledonous flowering plants $\sim 85$ million years ago (Les et al. 1997). They form meadows in shallow waters of the coastal zone, where they provide significant ecosystem functions and services (Orth et al. 2006) such as food and habitat for fauna (Heck et al. 2003), sediment stabilisation (Koch et al. 2006), carbon storage and high primary productivity (Orth et al. 2006, Lavery et al. 2013). Seagrasses have a high light requirement (Longstaff 1999) and their accelerating global decline has been attributed primarily to human activities that reduce light and water quality, such as eutrophication, sediment loading and dredging (Erftemeijer \& Robin Lewis 2006, Orth et al. 2006, Waycott et al. 2009), as well as climatic stochastic events (extreme temperatures and rainfall) (Fraser et al. 2014, Thomson et al. 2015). While the effects of reduced light intensity are well documented (Ralph et al. 2007, McMahon et al. 2013), very little is known about how shifts in light quality affect seagrass growth and reproduction (York et al. 2016).

The few studies carried out on seagrasses have demonstrated responses to shifts in light quality. In adult marine plants Ruppia maritima and Halodule wrightii, there are reports of reduced branching in both species and increased internode length in $H$.

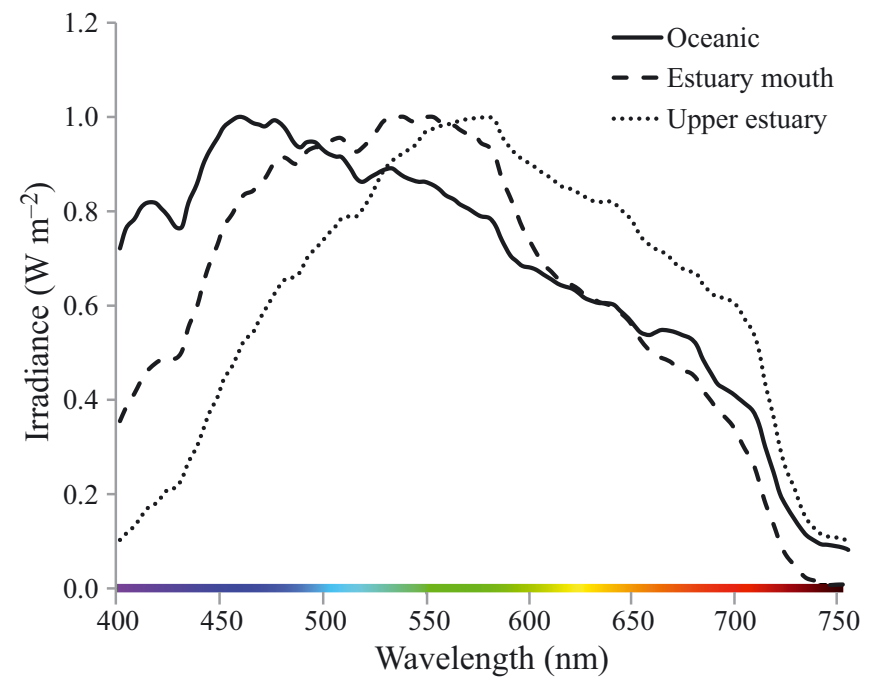

Fig. 2. Downwelling irradiance $\left(\mathrm{W} \mathrm{m}^{-2}\right)$ measured $1 \mathrm{~m}$ underwater at locations where seagrass meadows are present: an oceanic location (solid line), at the mouth of an estuary (dashed line) and in the upper reaches of an estuary (dotted line) (GPS coordinates in Table S3 in the Supplement at www.int-res.com/articles/suppl/m572p103_supp.pdf). These data were collected by S.S. and M. Slivkoff using a hyperspectral radiometer (USSIMO) from In-Situ Marine Optics in the Perth Coastal Waters and the Swan River Estuary

wrightii in response to a reduction of the red to far red ratio (R:FR) (Tomasko 1992, Rose \& Durako 1994). Seagrass seedlings Thalassia hemprichii exhibited enhanced growth in blue compared to red light (Soong et al. 2013), whereas the common response of many terrestrial angiosperms is enhanced seed germination under increased red light (in proportion to FR) (Vázquez-Yanes \& Smith 1982, Smith \& Whitelam 1997). This contrast hints at potential differences in the response of aquatic and terrestrial angiosperms to changes in light quality.

This study tested the responses of the widespread seagrass Halophila ovalis to monochromatic light treatments (blue, $\lambda=451 \mathrm{~nm}$; green, $\lambda=522 \mathrm{~nm}$; yellow, $\lambda=596 \mathrm{~nm}$; red, $\lambda=673 \mathrm{~nm}$ ). As light is considered the most important factor in controlling $H$. ovalis growth (Hillman et al. 1995), it was expected that biomass would be reduced in blue, green, yellow and red monochromatic light compared to full-spectrum light (at a constant light quantity) and that responses would not necessarily be consistent across the plant scale, i.e. some colours induce increases in photo-physiology variables (e.g. photosynthetic efficiency) but reduced biomass (relative to controls), as measured in terrestrial species (Fig. 1). To assess if the different life-history stages responded in the same way to different monochromatic light treatments, experiments were conducted on adult plants, seeds and seedlings. 


\section{MATERIALS AND METHODS}

In 3 separate experiments, the effect of monochromatic light quality treatments on different life-history phases of the seagrass Halophila ovalis - (1) adults, (2) seeds, and (3) seedlings - were tested.

\section{Adult experiment}

The single fixed factor 'Light quality' had 5 levels: full-spectrum ( $\lambda 400-700 \mathrm{~nm})$, blue (peak $\lambda=$ $451 \mathrm{~nm}$ ), green (peak $\lambda=522 \mathrm{~nm}$ ), yellow (peak $\lambda=$ $596 \mathrm{~nm}$ ) and red (peak $\lambda=673 \mathrm{~nm}$ ) light. For each level, 4 replicate aquarium tanks (54 l) were established (total $n=20$ independent glass tanks). Controls and treatments were randomly allocated, and each tank was isolated using PVC boards and shade cloth to ensure no leakage of light from surrounding treatments. Tanks were lined to $10 \mathrm{~cm}$ depth with unsorted washed quartz river sand containing $(1.3 \%)$ shredded seagrass wrack as a nutrient supply (Statton et al. 2013) and filled with 521 of seawater (salinity 35 ). The water in each tank was re-circulated through an individual sump with a pump and filter (300 $\mu \mathrm{m}$ foam block) ensuring each replicate tank was independent.

Light treatments were provided by aquarium lightemitting diode (LED) modules (MarinTech ${ }^{\mathrm{TM}}$ ) customised to a spectrum similar to sunlight on a $12 \mathrm{~h}$ light:12 h dark cycle. Each treatment was standardised to the same amount of photons (energy per photon per treatment is displayed in Table 1, and transmission spectra per treatment are displayed in Fig. S1 in the Supplement at www.int-res.com/articles/ suppl/m572p103_supp.pdf) and received $200 \mu \mathrm{mol}$ photons $\mathrm{m}^{-2} \mathrm{~s}^{-1}$ at the top of the canopy, measured by an underwater Li-Cor (LI-192) quantum sensor. Control tanks received light directly from the modules, and light quality treatments were imposed by placing colour filters (Rosco heat-resistant gel filter sheets) underneath the LED modules: Yellow using 'Canary Yellow', Red using 'Fire' and Blue using 'Night Blue'. However, for the green treatment, aquarium lights containing all green LEDs were used because the quantity could not be achieved using a filter. Light quality was measured using an underwater hyperspectral radiometer (USSIMO) from Insitu Marine Optics. Water temperature and salinity were monitored every $2 \mathrm{~d}$ using a conductivity meter $\left(\mathrm{WTW}^{\mathrm{TM}}\right)_{i}$ the temperature was maintained at 20 to $21^{\circ} \mathrm{C}$, and the salinity was maintained within 35 to 36 .
Table 1. The amount of energy per photon per light quality treatment (based on peak wavelength emission) that Halophila ovalis adults, seeds and seedlings were exposed to during the experiments. Note that energy was calculated as follows: $e=\mathrm{c} \cdot \mathrm{h} /(\lambda)$, where $e$ is energy in joules, $\mathrm{c}$ is light velocity $\left(299792458 \mathrm{~m} \mathrm{~s}^{-1}\right), \mathrm{h}$ is Planck's constant $\left(6.6260695729 \cdot 10^{-34}\right)$, and $\lambda$ is Lambda, which represents wavelength $(\mathrm{nm})$

\begin{tabular}{|lcc|}
\hline $\begin{array}{l}\text { Light quality } \\
\text { treatment }\end{array}$ & $\begin{array}{c}\text { Peak emission } \\
\lambda(\mathrm{nm})\end{array}$ & $\begin{array}{c}\text { Energy per } \\
\text { photon (Joules) }\end{array}$ \\
\hline Blue & 451 & $4.4045 \cdot 10^{-19}$ \\
Green & 522 & $3.8055 \cdot 10^{-19}$ \\
Yellow & 596 & $3.3330 \cdot 10^{-19}$ \\
Red & 673 & $2.9516 \cdot 10^{-19}$ \\
\hline
\end{tabular}

\section{Study site}

H. ovalis ramets were collected in August 2014 from close to the mouth of the Swan River estuary, southwest Western Australia ( $\left.32^{\circ} 01^{\prime} 49^{\prime \prime} \mathrm{S}, 115^{\circ} 45^{\prime} 46^{\prime \prime} \mathrm{E}\right)$, a temperate, estuarine habitat, where it is the dominant seagrass species and is greatly influenced by seasonal gradients (Hillman et al. 1995). Seasonal changes in water quality have been associated with periods of high rainfall (with $80 \%$ of the catchments rainfall occurring in the austral winter) which increase the concentrations of CDOM to the point where $66 \%$ of the variation in light attenuation within this estuary was explained by CDOM alone (Kostoglidis et al. 2005). Light quality and quantity at the site is influenced by seasonal periods of high CDOM concentrations (see upper estuary line in Fig. 2) but can also represent clear-oceanic downwelling irradiances (see oceanic line in Fig. 2), which demonstrates some of the spectral range to which $H$. ovalis is exposed at this site.

\section{Plant collection}

At the time of collection the salinity was 34 , and water temperature was $18^{\circ} \mathrm{C}$. Ramets with at least 5 leaf pairs behind the apical meristem were haphazardly collected by gently excavating the sediment at the edge of the meadow along a $1.5 \mathrm{~km}$ stretch to avoid spatial non-independence. They were stored in a container with seawater for transportation and planted within $2 \mathrm{~h}$ of collection. Ramets were standardised to 3 shoots behind the apical meristem (by cutting with a razor blade), and 10 were randomly assigned to each tank, planting at least $1 \mathrm{~cm}$ below the sediment surface. They were acclimated for $2 \mathrm{wk}$ under control conditions, as described above. To determine the health of plants prior to experimentation, the maxi- 
mum quantum yield of PSII was measured with a WALZ pulse amplitude modulated (PAM) diving fluorometer at the time of collection and after acclimation. Recorded values for both field and aquarium acclimated plants were similar and in the range identified as healthy, 0.73 to 0.75 , suggesting that aquarium plants had successfully acclimated (Ralph \& Burchett 1995). To determine growth rates over the experimental period, growing tips of each ramet were tagged by placing PVC-coated wire over the rhizome behind the youngest leaf pair.

\section{Experimental measurements}

At the end of the experiment (30 d), a range of measurements were taken reflecting different scales of plant response (Table 2). All ramets were gently removed from the tanks and stored at $-20^{\circ} \mathrm{C}$ (apart from pigment and carbohydrates samples which were stored in the dark at $-80^{\circ} \mathrm{C}$ ) prior to processing.

\section{Photosynthetic characteristics}

Before harvesting, photosynthetic characteristics were measured using rapid light curves on 3 mature leaves per tank. Leaf clips were placed adjacent to the central vein, and leaves were exposed to increasing photosynthetic photon flux density values $(0,3,11,45$, $70,102,179,271$ and $373 \mu \mathrm{mol}$ photons $\mathrm{m}^{-2} \mathrm{~s}^{-1}$ for 10 s) (Ralph \& Gademann 2005). PAM settings were as follows: measuring light: 8 , saturating pulse: 8 , gain: 5, and light curve width: $10 \mathrm{~s}$. The absorption factor (AF) for each leaf was determined following Beer \& Björk (2000), and the electron transport rates (ETR) were calculated following the standard rapid light curve protocol (Beer et al. 2001). The ETR-irradiance curves were fitted to the equation described by Jassby \& Platt (1976) to estimate ETR max $_{\text {, }}$ photosynthetic efficiency $(\alpha)$ and saturating irradiance $\left(E_{k}\right)$ using SigmaPlot (v7). In addition, the maximum quantum yield of PSII was measured on 3 mature leaves.

\section{Pigment analysis}

Chlorophyll $a$ and $b$ ( $\mu$ g pigment $\mathrm{g}^{-1} \mathrm{FW}$ leaf tissue) and the xanthophyll ancillary pigments were meas- ured following Collier (2006). Supernatants were analysed using high performance liquid chromatography (HPLC) comprised of a 600 controller, 717 plus refrigerated autosampler and a 996 photodiode array detector with a $\beta, \beta$ carotene standard. Chlorophyll concentrations were determined using equations based on Wellburn (1994), and the total xanthophyll concentrations were pooled.

\section{Biomass and leaf density}

For each tank, all plant material was harvested, rinsed in seawater, scraped free of epiphytes and leaves counted, then sorted into leaves plus petioles (above-ground) and rhizomes plus roots (belowground). Plant material was dried at $60^{\circ} \mathrm{C}$ for $48 \mathrm{~h}$, and the dry weight (DW) of each component was measured.

\section{Carbohydrates}

Carbohydrate analysis was performed on leaf and rhizome material from 3 pooled ramets per tank using a minimum weight of $75 \mathrm{mg}$ DW. Dried material was homogenized and ground into a fine powder, then leaf and rhizome samples were analysed separately for soluble sugars and starch content using enzymatic procedures adapted from McCleary \& Codd (1991). 


\section{Growth, morphology and reproduction}

A number of growth measures were estimated: leaf, root and rhizome productivity (mg DW apex ${ }^{-1}$ $\mathrm{d}^{-1}$ ), shoot production (shoot apex ${ }^{-1} \mathrm{~d}^{-1}$ ), shoot mortality (shoot apex $\left.{ }^{-1} \mathrm{~d}^{-1}\right)$, rhizome extension $\left(\mathrm{cm}\right.$ apex $^{-1}$ $\mathrm{d}^{-1}$ ) and branching rate (no. secondary branches) from tagged ramets.

Plants from each tank were photographed, and the images from 3 mature shoots behind the apex were used to measure leaf area $\left(\mathrm{cm}^{2}\right)$, petiole length $(\mathrm{cm})$, internode length $(\mathrm{cm})$ and root length $(\mathrm{cm})$ in the program Image J. A mean per tank was calculated.

Flowering occurred during the experiment, and the number of male and female flowers that emerged was counted over the period of the experiment.

\section{Seed germination experiment}

Whole fruits were collected in February 2015 from the same site as adults. They were incubated in the dark at $15^{\circ} \mathrm{C}$, as pilot work indicated germination did not occur under these conditions, until the fruits dehisced after $9 \mathrm{wk}$, then seeds were collected. In each tank, 10 circular plastic tubes were inserted into the sediment and 10 seeds planted just below the surface. The tubes marked the location of planted seeds allowing easy retrieval; they were not considered replicates. Care was taken to ensure that each seed was only exposed to the experimental light colour as small quantities of light can influence germination (Baskin et al. 2006); hence, there was no full-spectrum light acclimatisation period.

A protocol developed from preliminary $H$. ovalis seed germination experiments, which indicated that germination was maximised $(\sim 30 \%)$ with temperature 'ramping' ( $3 \mathrm{wk}$ at $15^{\circ} \mathrm{C}$, followed by $3 \mathrm{wk}$ at $20^{\circ} \mathrm{C}$, then 3 wk at $25^{\circ} \mathrm{C}$ J. Statton pers. comm.), was followed. The number of germinated seeds per tank was monitored daily by counting emergent leaves from the start of the $20^{\circ} \mathrm{C}$ ramping until the end of the experiment (14 July 2015). Then, 4 randomly selected tubes were removed and the number of germinated and viable seeds per tank counted. Germinated seeds were identified if the hypocotyl breached the seed coat, and viable seeds were identified with a squeeze test (Marion \& Orth 2010). Viable seeds are capable of germinating under suitable conditions, and non-viable seeds fail to germinate even under optimal conditions (Bradbeer 1988). The number of remaining viable seeds, number of germinated seeds and the percentage of viable seeds germinated was calculated for each tank.

\section{Seedling survival experiment}

The remaining 6 tubes per tank not harvested at the end of the seed germination experiment were left in place to assess seedling survival. However, due to the very low germination rates under blue $(0.005 \%)$ and green $(0.01 \%)$ light, these treatments could not be included in the experiment. For the red, yellow and control light treatments, seedling survival was assessed from the surviving 59 seedlings on a daily basis by recording the number of seedlings alive per tank over 4 wk (17 July to 8 August 2015).

\section{Statistical analyses}

A multivariate approach was taken to analyse the effect of light quality (fixed factor) on the response of adult plants using PRIMER v7 and PERMANOVA+ 2015 (PRIMER-E). Of the variables measured at the end of the adult experiment (see full list of 29 variables in Table S1 in the Supplement), a subset of 23 variables (Table 2) were selected based on an assessment of co-correlates. Once the related variables were removed, all 23 response variables identified in Table 2 were included and normalised. A test for homogeneity of variance was performed (PERMDISP) and a permutational analysis of variance (PERMANOVA) run on the resemblance matrix (created using Euclidean distance). Subsequently, a permutational pair-wise test was performed to determine which levels of treatment were significantly $(p<0.05)$ different from each other. For the significant pair-wise results, similarity percentage (SIMPER) analysis was then used to determine which response variables were contributing most to the differences. Individual PERMANOVAs were carried out on variables identified as important by the SIMPER analysis, to further confirm which levels of treatment were significantly $(p<0.05)$ different from each other at an individual response level (see Fig. 5). Originally, SIMPER was used to identify species driving patterns in multidimensional space, but it is also appropriate for other forms of data (Clarke et al. 2014). To illustrate the differences among treatments, a metric multidimensional scaling (mMDS) plot (Kruskal 1964) was created, and the average for each treatment with an $80 \%$ confidence interval was plotted using the Bootstrap Averages routine (Clarke \& Gorley 
2015). For the seed germination and seedling survival data, a univariate approach was used because there was only 1 response variable per experiment, yet it was still carried out in PRIMER and PERMANOVA as described above. However, as these analyses were univariate, a SIMPER and mMDS were not required.

\section{RESULTS}

\section{Adult experiment}

PERMANOVA indicated a significant $(\mathrm{p}<0.05)$ effect of light quality on adult Halophila ovalis plants (Table 3). The subsequent pair-wise PERMANOVA test indicated that all monochromatic light treatments, with the exception of red, were significantly $(p<0.05)$ different to the full-spectrum controls. Furthermore, the blue treatments were significantly different from the yellow treatments (Fig. 3, Table 3).

The SIMPER analysis indicated that the differences among light quality treatments were driven by a combination of physiological, growth, biomass and/or morphology variables (Table 4), with the relative importance of these variables differing according to the treatment. Overall, the short wavelength treatments (blue, green and yellow) differed to the controls, whereas long-wavelength radiation (red light) did not contribute to any of the differences among treatments. This pattern was evident from the MDS where red treatments grouped closer to the controls, whereas blue, green and yellow treatments grouped on the opposite end of the MDS1 axis (Fig. 3). In particular, below-ground productivity (root productivity, rhizome productivity and rhizome extension rate) declined in blue, green and yellow treatments compared to the controls. However, it was only in the blue light treatment where the reduction in root productivity was significantly lower than the controls and translated into a meadow scale response, with lower total biomass and leaf density (Figs. 4 \& 5, Table 4). Furthermore, changes in photosynthetic parameters were only observed under blue light, where the efficiency of photosynthesis $(\alpha)$ was significantly higher compared to full-spectrum light (Fig. 5). This result is further illustrated by the pattern of separation across the MDS1 axis (Fig. 3), which was greatest between control and blue treatments. Additionally, for green light, an increase in rhizome internode length was measured compared to the controls. The difference between blue and yellow treatments was mainly driven by photosynthetic
Table 3. Significant $(p<0.05)$ results from PERMANOVA analysis examining the effect of light quality (1 fixed factor) on response variables in the adult experiment

\begin{tabular}{|lccccc|}
\hline & df & MS & $F$ & $\begin{array}{c}\text { Unique } \\
\text { permutations }\end{array}$ & $\mathrm{p}$ \\
\hline Main test & & & & & \\
$\begin{array}{l}\text { Adult experiment } \\
\quad 19\end{array}$ & 40.45 & 2.2 & 999 & $<0.001$ \\
$\quad$ variables & & & & & \\
Significant pair-wise tests & & 35 & $<0.05$ \\
Control, Yellow & & & 35 & $<0.05$ \\
Control, Blue & & & 35 & $<0.05$ \\
Control, Green & & & 35 & $<0.05$ \\
Blue, Yellow & & & 35 & $<0.05$ \\
\hline
\end{tabular}

variables ( $\alpha$ and absorption factor), which were both higher in blue treatments. Additionally, ramet productivity and above-:belowground biomass ratio were inversely related among light quality treatments (see Fig. S2 in the Supplement). Several of the aforementioned patterns are simplified in univariate plots (Fig. 5).

\section{Seed germination experiment}

There was a significant effect of monochromatic light treatment on the germination of viable $H$. ovalis seeds $(\mathrm{df}=19, F=11.08,999$ unique permutations, $\mathrm{p}<0.01$ ), with controls significantly higher than the green and blue treatments (Fig. 6A). Significantly higher germination occurred in red compared to blue (unique perm $5, \mathrm{p}<0.05$ ) and green (unique perm 7 ,

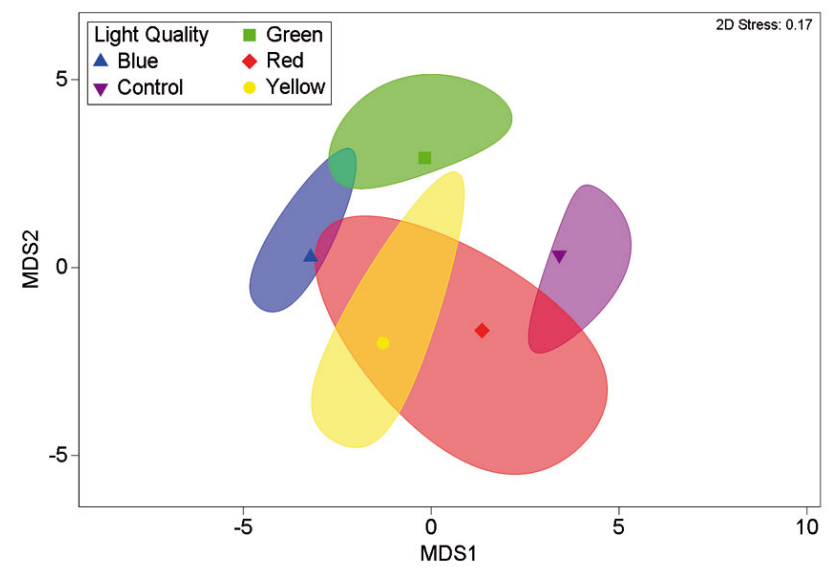

Fig. 3. 2-D mMDS displays the group means surrounded by a corresponding bootstrap region (with $80 \%$ confidence interval at 100 bootstraps per group) of the replicate $H$. ovalis adult plant samples grown under different light quality treatments 
Table 4. SIMPER summary table indicating which variables contributed to the observed average distances between the light quality treatment groups (cumulative \% cut-off at $30 \%$ )

\begin{tabular}{|c|c|c|c|c|c|c|}
\hline Treatment groups & Response variable & $\begin{array}{l}\text { Mean } \\
\text { value }\end{array}$ & $\begin{array}{l}\text { Mean } \\
\text { value }\end{array}$ & $\begin{array}{c}\text { Square } \\
\text { distance (SD) }\end{array}$ & $\begin{array}{c}\text { Contribution } \\
\%\end{array}$ & $\begin{array}{c}\text { Cumulative } \\
\%\end{array}$ \\
\hline \multirow{4}{*}{ Control vs. Yellow } & & Control & Yellow & & & \\
\hline & Rhizome productivity & 1.66 & -0.798 & 1.42 & 13.19 & 13.19 \\
\hline & Root productivity & 1.46 & -0.733 & 1.25 & 10.78 & 23.97 \\
\hline & Rhizome extension rate & 1.41 & -0.774 & 1.77 & 10.04 & 34.00 \\
\hline \multirow{5}{*}{ Control vs. Blue } & & Control & Blue & & & \\
\hline & Root productivity & 1.46 & -0.735 & 1.24 & 11.35 & 11.35 \\
\hline & Total biomass & 1.07 & -0.823 & 1.31 & 8.56 & 19.91 \\
\hline & Alpha $(\alpha)$ & -0.258 & 1.76 & 2.48 & 8.47 & 28.38 \\
\hline & Leaf density & 0.876 & -0.631 & 1.30 & 7.93 & 36.31 \\
\hline \multirow{5}{*}{ Control vs. Green } & & Control & Green & & & \\
\hline & Rhizome productivity & 1.66 & -0.294 & 1.40 & 9.06 & 9.06 \\
\hline & Rhizome extension rate & 1.41 & -0.352 & 1.14 & 8.67 & 17.73 \\
\hline & Root productivity & 1.46 & -0.127 & 0.92 & 7.95 & 25.68 \\
\hline & Internode length & 0.133 & 0.4 & 0.89 & 7.22 & 32.91 \\
\hline \multirow{4}{*}{ Blue vs. Yellow } & & Blue & Yellow & & & \\
\hline & Alpha $(\alpha)$ & 1.76 & -0.769 & 3.30 & 15.15 & 15.15 \\
\hline & Absorption factor & 1.32 & -0.558 & 1.12 & 10.69 & 25.84 \\
\hline & Above-:below ground biomass ratio & -0.516 & 0.75 & 1.04 & 8.06 & 33.89 \\
\hline
\end{tabular}

$\mathrm{p}<0.05)$ treatments. Similarly, significantly higher germination in yellow occurred compared to the blue (unique perm 6, p < 0.05) treatments (see Table S2 in the Supplement).

\section{Seedling survival experiment}

A significant effect of monochromatic light treatments was also detected for seedling survival over $23 \mathrm{~d}(\mathrm{df}=11, F=5.9$, unique perm $144, \mathrm{p}<0.05)$. Seedling survival was significantly higher in the red treatments compared to the controls (unique perm 8 , $\mathrm{p}<0.05$ ), with yellow intermediate and not significantly different to either the controls or red light treatment (Fig. 6B, Table S2).

\section{DISCUSSION}

This study demonstrated that Halophila ovalis is sensitive to yellow, green and blue wavelengths that negatively impacted below-ground productivity and led to decreased biomass under blue light (Fig. 4). Furthermore, seed germination and seedling survival were enhanced by red and yellow light. The

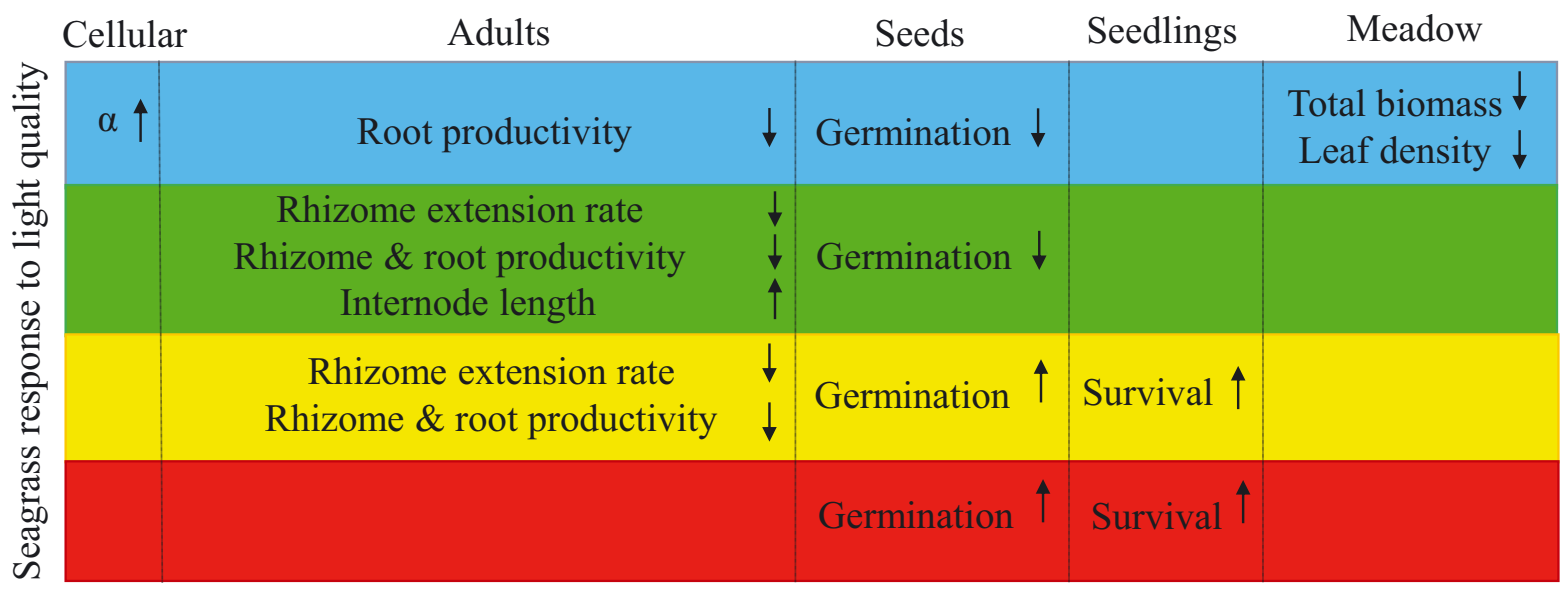

Fig. 4. Summary of Halophila ovalis photo-physiology, adult plant, meadow scale, seed germination (\%) and seedling survival (\%) responses (arrows) to monochromatic (blue, green, yellow and red) light quality treatments compared to fullspectrum light 

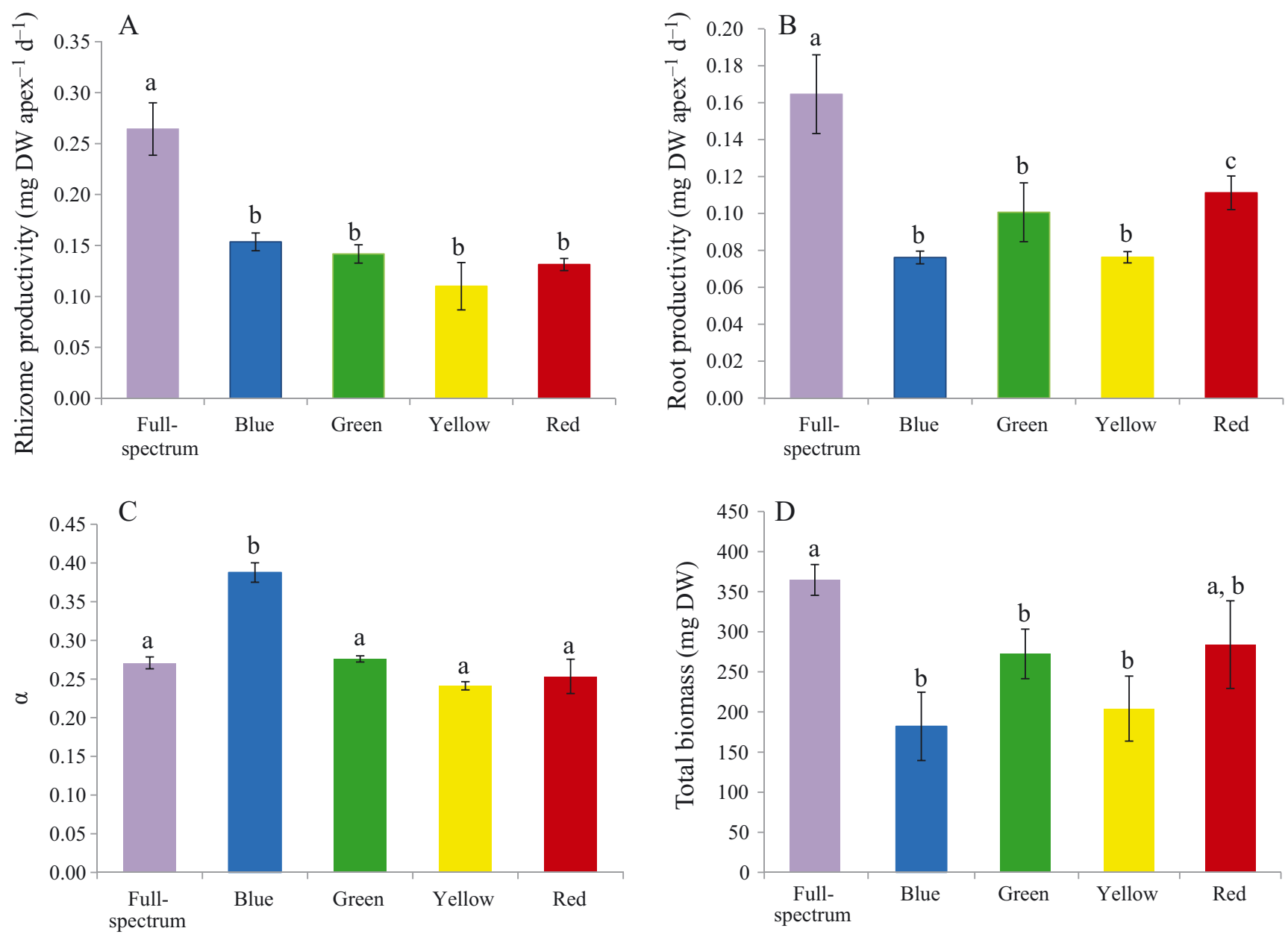

Fig. 5. H. ovalis mean $( \pm 1 \mathrm{SE})$ values of $(\mathrm{A})$ rhizome productivity, (B) root productivity, (C) photosynthetic efficiency $(\alpha)$ and $(\mathrm{D})$ total biomass in response to monochromatic and full-spectrum light. Different lowercase letters denote significant differences $(\mathrm{p}<0.05)$ among values
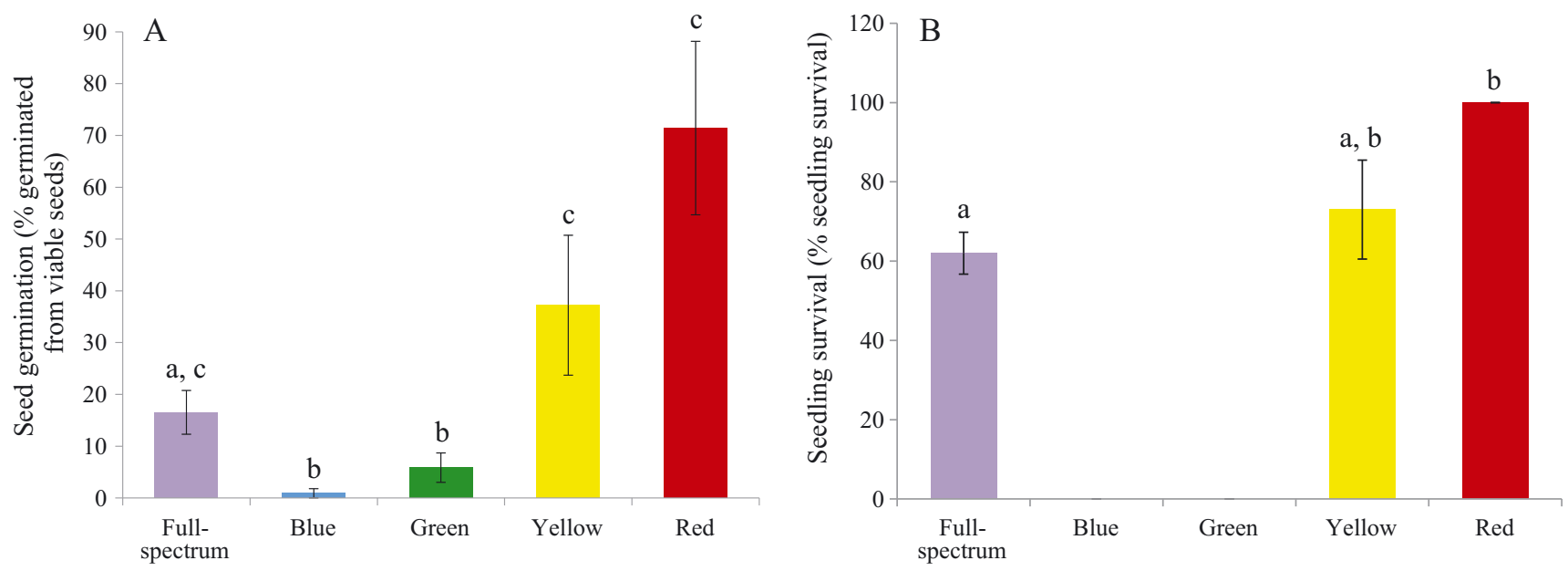

Fig. 6. H. ovalis mean ( $\pm 1 \mathrm{SE})(\mathrm{A})$ seed germination and (B) seedling survival in response to monochromatic and full-spectrum light. Different lowercase letters denote significant differences $(p<0.05)$ among values. Blue and green treatments were not conducted in the seedling survival experiment 
responses of different life-history stages of $H$. ovalis to monochromatic light quality varied, yet in general were congruent with terrestrial plant responses. This suggests the underlying mechanisms driving light quality responses in terrestrial plants (i.e. photoreceptors) are present in seagrasses, despite 85 million years of evolution in environments with different light characteristics.

\section{Adult experiment}

A significant negative effect on $H$. ovalis plants was observed in blue light where reduced root productivity, which has been measured in other studies of terrestrial plants (Victorio \& Lage 2009, Baque et al. 2011), led to a reduction in biomass and leaf density compared to controls. However, the higher photosynthetic efficiency $(\alpha)$ in the blue treatments did not result in an increased $\mathrm{ETR}_{\max }$, which suggests that the increase in $\alpha$ was an adjustment to attempt to maintain a positive carbon balance as reported for riverine $H$. johnsonni (Kahn \& Durako 2009). Similarly, H. johnsonii populations from riverine locations (strongly influenced by CDOM) exhibited higher gross photosynthetic rates and quantum efficiencies than marine inlet plants (low-CDOM environment) at the short wavelengths (350, 400 and $450 \mathrm{~nm})$ (Kahn \& Durako 2009). Furthermore, we also suggest that the increased photosynthetic efficiency in the blue treatment could have been due to the nature of blue light, specifically, due to its higher frequency as it has more energy per photon than red light. However, this may not have led to increased $\mathrm{ETR}_{\max }$, due to the possibility of non-photochemical quenching and photoinhibition (Sun et al. 1998).

Our results also show reduced below-ground productivity (rhizomes and roots) under yellow and green light, but this did not lead to significantly lower biomass compared to plants growing under control light. This may indicate a switch between belowground production to above-ground production in an attempt to acclimate to green and yellow light conditions.

It was previously assumed that green light was inefficient at driving photosynthesis because of its low absorption by chlorophyll; however, there is now evidence suggesting that green light supports photosynthesis within deep-tissue chloroplasts (Sun et al. 1998) and the rate of photosynthesis is capable of supporting plant growth at saturating intensities of green light (i.e. 100 to $200 \mu \mathrm{mol}$ photons $\mathrm{m}^{-2} \mathrm{~s}^{-1}$ ) (Golovatskaya \& Karnachuk 2015). Whilst seagrasses have chloroplasts in the epidermal cell layers (Tomlinson 1980), the reflected green light within these chloroplasts could be absorbed as it is in terrestrial leaves (Sun et al. 1998). For example, a study of another seagrass, Zostera marina, used layers of green algae Ulva intestinalis to alter the quality of light received by the seagrass towards green and showed that saturating irradiance and $\mathrm{ETR}_{\max }$ were not significantly impacted (Mvungi et al. 2012). Some pigments, such as carotenoids, absorb green light and transfer excited photons to reaction centres to be used in photosynthesis (Salisbury \& Ross 1992), and such pigments have been shown to increase electron transport in Amaranthus cruentus (Ptushenko et al. 2002). Our research also did not find a strong effect of green, yellow and red light on photosynthetic performance or pigment content compared to control light; therefore, these monochromatic light conditions may be effective at driving seagrass photosynthesis using the same underlying mechanisms that are present in terrestrial angiosperms.

The discrepancy between the lack of photosynthetic response in yellow and green light and a reduced productivity response in this experiment was evident in other studies. For example, lettuce Lactuca sativa grown under broad spectrum light (blue-greenyellow-red) had a higher biomass compared to plants grown under green fluorescent light (500 to $600 \mathrm{~nm}$ ), although there was no significant difference in chlorophyll content between the treatments (Kim et al. 2004). Similarly, green and yellow treatments significantly impacted cucumber Cucumis sativus growth but not chlorophyll content when compared to a broad spectrum white light (Al-Wakeel \& Hamed 1996, Su et al. 2014). Another experiment suggests that yellow light suppresses chlorophyll and chloroplast formation in lettuce (Dougher \& Bugbee 2001), which may have explained the inhibition of plant growth under yellow light. There may be an underlying mechanism that was not measured in this study that could account for the discrepancy between physiology and growth responses, such as chloroplast formation/ structure, Rubisco content, cell expansion or phytohormone concentrations (auxins, gibberellins, etc.) (Dougher \& Bugbee 2001, 2004, Drozdova et al. 2001, Canamero et al. 2006). Alternatively, the discrepancy could relate to the use of the PAM fluorometer to measure photosynthetic characteristics. PAM fluorometers emit bursts of white light to measure photosynthetic characteristics, and, therefore, the responses measured may not reflect those under the treatment to which the plant has been subjected (i.e. monochromatic green or yellow light). Consequently, the 
actinic light may have confounded the photosynthetic response measured (in this study and in those mentioned above), and future studies should use actinic light sources that are the same light quality as the one under which the plants are being treated (Kim et al. 2004).

An interesting finding was observed in the green light treatments where rhizome internodes were longer than in the controls, despite the lowered overall below-ground biomass that was produced. This type of morphological response is similar to the 'shade avoidance response' (Casal 2012) where terrestrial plant form (and gene expression) is altered to best suit shade light, predominantly green and far-red light (Klein 1992, Stamm \& Kumar 2010). The green-absorbing form of cryptochrome (cry1 and cry2) and an unknown green light photoreceptor may be the underlying mechanism behind these plant responses (Folta 2004, Banerjee et al. 2007, Zhang et al. 2011). Green light could provide an additional function similar to R:FR light in that it is crucial for informing the plant of unfavourable light conditions (Folta \& Maruhnich 2007). In the marine environment, increased suspended sediment loads within the water column (Kirk 1994, Longstaff 1999) reduce light quantity (Erftemeijer \& Robin Lewis 2006) and shift the spectra towards green initially, then yellow with increased suspended sediment loads (Chartrand et al. 2012, Jones et al. 2016). The poor growth response of adult $H$. ovalis to monochromatic yellow and green light may therefore reflect the likely response to a yellow-green shift under turbidity plumes.

\section{Seed experiment}

The enhanced germination rate of $H$. ovalis seeds under red light and low germination under blue light was analogous to the response of Myriophyllum spicatum (a submerged freshwater angiosperm) to monochromatic light quality (Coble \& Vance 1987). Conversely, our results differ from a light quality experiment conducted on Thalassia hemprichii (seagrass species) which observed no significant effect of red light on early seedling leaf growth (Soong et al. 2013). As it is widely accepted that phytochromes are important for mediating red light responses in terrestrial plants, and that increases in R:FR often enhance seed germination rates (Whitelam \& Smith 1991, Smith \& Whitelam 1997), perhaps phytochrome is active in $H$. ovalis, as it seems to be in both $H$. wrightii (Tomasko 1992) and $R$. maritima (Rose \& Durako 1994). Whilst photoreceptor analysis was beyond the scope of this study, it is likely that this mechanism could be similar for $H$. ovalis in that a higher proportion of red light indicates shallow or clear water or a gap in the meadow canopy and, therefore, conditions conducive for germination and subsequent seedling survival. Further studies of the $H$. ovalis and T. hemprichii phytochrome or genome sequencing would be required to confirm whether phytochrome is absent in these species, as has been determined in the seagrass Zostera marina (Olsen et al. 2016), and whether the same mechanisms that influence seed germination in terrestrial plants are active in the germination of seagrass seeds.

\section{Seedling experiment}

High seedling survival in red $(100 \%)$ and yellow $(73 \%)$ light indicates that different life-history stages in $H$. ovalis are adapted to respond to different light quality cues in the environment. These could be influenced by seasonal changes in freshwater inputs and runoff into estuaries and coastal seas that result in large changes in salinity, nutrients, turbidity, CDOM and phytoplankton blooms (Kirk 1994). This response contrasts with that of adult plants, which responded negatively to yellow light, suggesting maximum growth is linked to reduced freshwater inputs, reflecting summer conditions in temperate estuarine systems.

Seed germination, seedling survival and adult responses may be influenced by seasonal shifts in water quality within the Swan River Estuary. For example, seed germination was reduced under blue and green light and both seed germination and seedling survival were enhanced by red and yellow light, which may reflect this species' adaptation to a yellow- and red-enriched light climate when seeds are released. $H$. ovalis fruits mature and release seeds between February and April (Kuo \& Kirkman 1992), and the high rainfall season occurs from May to August; therefore, this timing coincides with the increase in CDOM and the subsequent shift to yellow/red light-perhaps the enhanced germination of seeds reflects a response to their environment. The adult response may also reflect seasonal changes in water quality as high CDOM levels in the Swan River Estuary during winter shift light quality towards yellow, which coincides with the decline in growth pattern of $H$. ovalis, further suggesting maximum growth is highly linked to reduced freshwater inputs (and increased temperatures) later in the summer. Blue light negatively impacted both adults and 
seeds. Perhaps the seasonal high attenuation of blue light has led the population of $H$. ovalis growing within the Swan River Estuary $(<2 \mathrm{~m})$ to acclimate to relatively red/yellow-shifted light, which may explain their poor response to monochromatic blue light. Furthermore, the poor response to blue light may also be linked to photo damage from the highenergy wavelengths. $H$. ovalis also grows in oceanic deep-water environments, where blue and green light dominate, but the light quantity at depth is naturally reduced. Therefore, these findings need to be considered in light of the study site and the fact that it is possible that local acclimation may produce slightly different responses in other locations. A clear example of a seagrass' ability to acclimate to local conditions was a reciprocal transplantation experiment of riverine and marine inlet $H$. johnsonni populations, where rapid changes in photobiology and UV-absorbing pigment levels occurred within just $4 \mathrm{~d}$ (Durako et al. 2003).

It is important to acknowledge that in this experiment, the plants were treated with monochromatic light in order to determine if $H$. ovalis is sensitive to changes in light quality. In reality, marine plants are not subjected to such narrow wavelength bands; they would be exposed to light dominated by a certain colour with a mixture of other wavelengths depending on water quality conditions (Fig. 2). For example, high concentrations of CDOM cause the water to take on a yellow appearance, due to the stronger attenuation of the shorter wavelength of blue light (Stedmon et al. 2000), and in chlorophyll-enriched waters, red light and, to a lesser extent, blue is highly attenuated (Kirk 1994). Therefore, while the results in this paper show that $H$. ovalis does respond to monochromatic light, the magnitude of the response under natural conditions, when plants receive a combination of wavelengths under a range of water quality conditions, may be more subtle. The responses may vary according to acclimation to local habitat, and such acclimation is therefore an area that warrants investigation.

\section{CONCLUSIONS}

This research demonstrates that blue, yellow and green light negatively impact growth of $H$. ovalis adults (predominantly below-ground productivity) but not seed germination or seedling survival, suggesting a life-history that is influenced by spectral shifts in light. Furthermore, green or yellow light did not significantly affect photosynthesis at saturating irradiances; however, it must be considered that light intensity is reduced under turbidity plumes, and therefore, the interaction of these variables should be investigated. Processes that affect light quality towards the blue (i.e. deep-water) or yellow-green region, such as dredging or river discharges high in CDOM concentrations, could negatively impact seagrass meadows through both reduced light quantity and an altered spectrum. Therefore, information on light quality conditions that enhance or impact survival of different life history stages is relevant for the conservation and management of marine plants, particularly restoration efforts. Whilst none of the spectra caused mass death, the photosynthetic response to light spectral limitations is subtle and signifies the plasticity of $H$. ovalis.

Acknowledgements. This research was partially funded by the Western Australian Marine Science Institute and through the Australian Commonwealth Government's Collaborative Research networks scheme (Grant CRN2011:05) and the School of Sciences, Edith Cowan University. Thank you to Dr. Matthew Slivkoff and Dr. Wojciech Klonowski at In-Situ Marine Optics for use of their hyperspectral radiometer (USSIMO). We are also indebted to Jeramie Putman for his help with fieldwork, aquarium construction and processing seagrass samples. This work was carried out at the Challenger TAFE aquaculture facility and at Edith Cowan University in Western Australia.

\section{LITERATURE CITED}

Al-Wakeel S, Hamed A (1996) Light-quality effect on growth and some biochemical aspects of mild-stressed Cucurbita pepo L. Egypt J Bot 36:217-234

Alvarenga ICA, Pacheco FV, Silva ST, Bertolucci SKV, Pinto JEBP (2015) In vitro culture of Achillea millefolium L.: quality and intensity of light on growth and production of volatiles. Plant Cell Tissue Organ Cult 122:299-308

* Banerjee R, Schleicher E, Meier S, Viana RM and others (2007) The signaling state of Arabidopsis cryptochrome 2 contains flavin semiquinone. J Biol Chem 282: 14916-14922

Baque MA, Shin YK, Elshmari T, Lee EJ, Paek KY (2011) Effect of light quality, sucrose and coconut water concentration on the micropropagation of Calanthe hybrids ('Bukduseong' $\mathrm{x}$ 'Hyesung' and 'Chunkwang' $\mathrm{x}$ 'Hyesung'). Aust J Crop Sci 5:1247-1254

Baskin CC, Thompson KM, Baskin J (2006) Mistakes in germination ecology and how to avoid them. Seed Sci Res 16:165-168

Beer S, Björk M (2000) Measuring rates of photosynthesis of two tropical seagrasses by pulse amplitude modulated (PAM) fluorometry. Aquat Bot 66:69-76

Beer S, Björk M, Gademann R, Ralph PJ (2001) Measurements of photosynthetic rates in seagrasses. In: Short F, Coles RG (eds) Global seagrass research methods. Elsevier, Amsterdam, p 183-198

Bradbeer JW (ed) (1988) Seed viability and vigour. In: Seed dormancy and germination. Chapman \& Hall, New York, NY, p 95-109 
Canamero RC, Bakrim N, Bouly JP, Garay A, Dudkin EE, Habricot Y, Ahmad M (2006) Cryptochrome photoreceptors cry 1 and cry 2 antagonistically regulate primary root elongation in Arabidopsis thaliana. Planta 224: 995-1003

Casal JJ (2000) Phytochromes, cryptochromes, phototropin: photorecepter interactions in plants. Photochem Photobiol 71:1-11

Casal JJ (2012) Shade avoidance. The Arabidopsis book. Am Soc Plant Biol 10:e0157

Chartrand KM, Rasheed MA, Katherina P, Ralph P (2012) Establishing tropical seagrass light requirements in a dynamic port environment. In: Yellowlees D, Hughes TP (eds) Proc 12th Int Coral Reef Symp. Seagrasses and Seagrass Ecosystems, 9-13 Jul 2012, James Cook University Townsville, ICRS2012_15B_1

Clarke KR, Gorley RN (2015) PRIMER v7: user manual/ tutorial. PRIMER-E, Plymouth

Clarke KR, Tweedley JR, Valesini FJ (2014) Simple shade plots aid better long-term choices of data pre-treatment in multivariate assemblage studies. J Mar Biol Assoc UK 94:1-16

Coble TA, Vance BD (1987) Seed germination in Myriophyllum spicatum L. J Aquat Plant Manag 25:8-10

Collier CJ (2006) Characterising responses of the seagrass Posidonia sinuosa to changes in light availability. $\mathrm{PhD}$ dissertation, Edith Cowan University, Perth

Dougher TAO, Bugbee B (2001) Evidence for yellow light suppression of lettuce growth. Photochem Photobiol 73: 208-212

Dougher TA, Bugbee B (2004) Long-term blue light effects on the histology of lettuce and soybean leaves and stems. J Am Soc Hortic Sci 129:467-472

Drozdova IS, Bondar VV, Bukhov NG, Kotov AA, Kotova LM, Maevskaya SN, Mokronosov AT (2001) Effects of light spectral quality on morphogenesis and source-sink relations in radish plants. Russ J Plant Physiol 48: 415-420

Durako MJ, Kunzelman J, Kenworthy W, Hammerstrom K (2003) Depth-related variability in the photobiology of two populations of Halophila johnsonii and Halophila decipiens. Mar Biol 142:1219-1228

Erftemeijer PLA, Robin Lewis R III (2006) Environmental impacts of dredging on seagrasses: a review. Mar Pollut Bull 52:1553-1572

Fankhauser C, Chory J (1997) Light control of plant development. Annu Rev Cell Dev Biol 13:203-229

Folta KM (2004) Green light stimulates early stem elongation, antagonizing light-mediated growth inhibition. Plant Physiol 135:1407-1416

Folta KM, Maruhnich SA (2007) Green light: a signal to slow down or stop. J Exp Bot 58:3099-3111

* Fraser MW, Kendrick GA, Statton J, Hovey RK, ZavalaPerez A, Walker DI (2014) Extreme climate events lower resilience of foundation seagrass at edge of biogeographical range. J Ecol 102:1528-1536

Golovatskaya IF, Karnachuk RA (2015) Role of green light in physiological activity of plants. Russ J Plant Physiol 62: $727-740$

*Guo Y, Gu A, Cui J (2011) Effects of light quality on rice seedlings growth and physiological characteristics. Ying Yong Sheng Tai Xue Bao 22:1485-1492 (in Chinese)

Heck KL Jr, Hays G, Orth RJ (2003) Critical evaluation of the nursery role hypothesis for seagrass meadows. Mar Ecol Prog Ser 253:123-136
Hillman K, McComb A, Walker D (1995) The distribution, biomass and primary production of the seagrass Halophila ovalis in the Swan/Canning Estuary, Western Australia. Aquat Bot 51:1-54

Islam MO, Matsui S, Ichihashi S (1999) Effects of light qualify on seed germination and seedling growth of Cattleya orchids in vitro. J Jpn Soc Hortic Sci 68:1132-1138

Jassby AD, Platt T (1976) Mathematical formulation of the relationship between photosynthesis and light for phytoplankton. Limnol Oceanogr 21:540-547

Jones R, Bessell-Browne P, Fisher R, Klonowski W, Slivkoff $M$ (2016) Assessing the impacts of sediments from dredging on corals. Mar Pollut Bull 102:9-29

Kahn AE, Durako MJ (2009) Wavelength-specific photosynthetic responses of Halophila johnsonii from marineinfluenced versus river-influenced habitats. Aquat Bot 91:245-249

Kim HH, Goins GD, Wheeler RM, Sager JC (2004) Greenlight supplementation for enhanced lettuce growth under red-and blue-light-emitting diodes. HortScience 39:1617-1622

Kirk J (1994) Light and photosynthesis in aquatic ecosystems. Cambridge University Press, Cambridge

Klein RM (1992) Effects of green light on biological systems. Biol Rev Camb Philos Soc 67:199-284

Koch EW, Sanford LP, Chen S, Shafer DJ, Smith JM (2006) Waves in seagrass systems: review and technical recommendations (ERDC-TR-06-15). University of Maryland, Cambridge, MD

Kopsell DA, Sams CE (2013) Increases in shoot tissue pigments, glucosinolates, and mineral elements in sprouting broccoli after exposure to short-duration blue light from light emitting diodes. J Am Soc Hortic Sci 138:31-37

Kostoglidis A, Pattiaratchi C, Hamilton D (2005) CDOM and its contribution to the underwater light climate of a shallow, microtidal estuary in south-western Australia. Estuar Coast Shelf Sci 63:469-477

Kruskal JB (1964) Multidimensional scaling by optimizing goodness of fit to a nonmetric hypothesis. Psychometrika 29:1-27

Kuo J, Kirkman H (1992) Fruits, seeds and germination in Halophila ovalis. Bot Mar 35:197-204

Kavery PS, Mateo MÁ, Serrano O, Rozaimi M (2013) Variability in the carbon storage of seagrass habitats and its implications for global estimates of blue carbon ecosystem service. PLOS ONE 8:e73748

Kee Y, Fang W, Chen C (2011) Effect of six different LED light qualities on the seedling growth of Paphiopedilum orchid in vitro. Proc VI Int Symp Light in Horticulture. Acta Hortic 389-391

Les DH, Cleland MA, Waycott M (1997) Phylogenetic studies in Alismatidae, II: evolution of marine angiosperms (seagrasses) and hydrophily. Syst Bot 22:443-463

Longstaff BJ (1999) Investigations into the light requirements of seagrasses in Northeast Australia. PhD dissertation, University of Queensland, Brisbane

Luna B, Pérez B, Fernández-González F, Moreno J (2004) Sensitivity to green safelight of 12 Mediterranean species. Seed Sci Technol 32:113-117

* Marion SR, Orth RJ (2010) Innovative techniques for large scale seagrass restoration using Zostera marina (eelgrass) seeds. Restor Ecol 18:514-526

* McCleary B, Codd R (1991) Measurement of $(1 \rightarrow 3),(1 \rightarrow 4)-\beta$ D-glucan in barley and oats: a streamlined enzymic procedure. J Sci Food Agric 55:303-312 
McMahon K, Collier CJ, Lavery PS (2013) Identifying robust bioindicators of light stress in seagrasses: a meta-analysis. Ecol Indic 30:7-15

Mvungi EF, Lyimo TJ, Björk M (2012) When Zostera marina is intermixed with Ulva, its photosynthesis is reduced by increased $\mathrm{pH}$ and lower light, but not by changes in light quality. Aquat Bot 102:44-49

Neff MM, Fankhauser C, Chory J (2000) Light: an indicator of time and place. Genes Dev 14:257-271

Nowak J, Rudnicki RM, Grzesik M (1996) Effect of light quality on seed germination, seedling growth and pigment content in Amaranthus caudatus and Celosia cristata nana. J Fruit Orn Plant Res (Poland) 4:179-185

* Olsen JL, Rouzé P, Verhelst B, Lin YC and others (2016) The genome of the seagrass Zostera marina reveals angiosperm adaptation to the sea. Nature 530:331-335

* Orth RJ, Carruthers TJB, Dennison WC, Duarte CM and others (2006) A global crisis for seagrass ecosystems. Bioscience 56:987-996

Ptushenko V, Gins M, Gins V, Tikhonov A (2002) Interaction of amaranthin with the electron transport chain of chloroplasts. Russ J Plant Physiol 49:585-591

Qi-He Y, Wan-Hui Y, Xiong D, Hong-Ling C, Zhang Y, KaiYang X (2005) Seed germination eco-physiology of Mikania micrantha HBK. Bot Bull Acad Sin 46:293-299

Ralph PJ, Burchett MD (1995) Photosynthetic responses of the seagrass Halophila ovalis (R. Br.) Hook. f. to high irradiance stress, using chlorophyll a fluorescence. Aquat Bot 51:55-66

Ralph PJ, Gademann R (2005) Rapid light curves: a powerful tool to assess photosynthetic activity. Aquat Bot 82:222-237

Ralph PJ, Durako MJ, Enríquez S, Collier CJ, Doblin MA (2007) Impact of light limitation on seagrasses. J Exp Mar Biol Ecol 350:176-193

Rose CD, Durako MJ (1994) Induced photomorphogenesis by an altered R-FR light ratio in axenic Ruppia maritima L. Bot Mar 37:531-535

Salisbury FB, Ross CW (1992) Plant physiology. Wadsworth Publishing, Belmont, CA

Smith H, Whitelam GC (1997) The shade avoidance syndrome: multiple responses mediated by multiple phytochromes. Plant Cell Environ 20:840-844

Soong K, Chiu S, Chen C (2013) Novel seed adaptations of a monocotyledon seagrass in the wavy sea. PLOS ONE 8: e74143

Stamm P, Kumar PP (2010) The phytohormone signal network regulating elongation growth during shade avoidance. J Exp Bot 61:2889-2903

Statton J, Cambridge ML, Dixon KW, Kendrick GA (2013) Aquaculture of Posidonia australis seedlings for seagrass restoration programs: effect of sediment type and organic enrichment on growth. Restor Ecol 21: 250-259

Stedmon C, Markager S, Kaas H (2000) Optical properties and signatures of chromophoric dissolved organic matter

Editorial responsibility: Morten Pedersen,

Roskilde, Denmark
(CDOM) in Danish coastal waters. Estuar Coast Shelf Sci 51:267-278

Su N, Wu Q, Shen Z, Xia K, Cui J (2014) Effects of light quality on the chloroplastic ultrastructure and photosynthetic characteristics of cucumber seedlings. J Plant Growth Regul 73:227-235

* Sun J, Nishio JN, Vogelmann TC (1998) Green light drives $\mathrm{CO}_{2}$ fixation deep within leaves. Plant Cell Physiol 39: 1020-1026

*Thomson JA, Burkholder DA, Heithaus MR, Fourqurean JW, Fraser MW, Statton J, Kendrick GA (2015) Extreme temperatures, foundation species, and abrupt ecosystem change: an example from an iconic seagrass ecosystem. Glob Chang Biol 21:1463-1474

* Tomasko DA (1992) Variation in growth form of shoal grass (Halodule wrightii) due to changes in the spectral composition of light below a canopy of turtle grass (Thalassia testudinum). Estuaries 15:214-217

Tomlinson PB (1980) Leaf morphology and anatomy in seagrasses. In: Phillips R, McRoy C (eds) Handbook of seagrass biology: an ecosystem perspective. Garland Press, New York, NY

*Vázquez-Yanes C, Smith H (1982) Phytochrome control of seed germination in the tropical rain forest pioneer trees Cecropia obtusifolia and Piper auritum and its ecological significance. New Phytol 92:477-485

Victorio CP, Lage CLS (2009) Light quality effects on germination and initial development in vitro of Phyllanthus tenellus. Revista Ciência Agronômica 40:400-405

Walck JL, Baskin JM, Baskin CC (2000) Increased sensitivity to green light during transition from conditional dormancy to nondormancy in seeds of three species of Solidago (Asteraceae). Seed Sci Res 10:495-499

Waycott M, Duarte CM, Carruthers TJB, Orth RJ and others (2009) Accelerating loss of seagrasses across the globe threatens coastal ecosystems. Proc Natl Acad Sci USA 106:12377-12381

*Wellburn AR (1994) The spectral determination of chlorophylls $a$ and $b$, as well as total carotenoids, using various solvents with spectrophotometers of different resolution. J Plant Physiol 144:307-313

Whitelam GC, Halliday KJ (2008) Annual plant reviews, light and plant development, Vol 30. John Wiley \& Sons, Hoboken, NJ

Whitelam GC, Smith H (1991) Retention of phytochromemediated shade avoidance responses in phytochromedeficient mutants of Arabidopsis, cucumber and tomato. J Plant Physiol 139:119-125

York PH, Smith TM, Coles RG, McKenna SA and others (2016) Identifying knowledge gaps in seagrass research and management: an Australian perspective. Mar Environ Res (in press)

Khang T, Maruhnich SA, Folta KM (2011) Green light induces shade avoidance symptoms. Plant Physiol 157: 1528-1536

Submitted: August 29, 2016; Accepted: March 1, 2017

Proofs received from author(s): April 28, 2017 